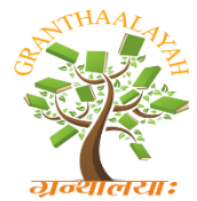

\author{
INTERNATIONAL JOURNAL OF RE
GRANTHAALAYAH \\ A knowledge Repository
}

Science

\title{
EVALUATION OF OVERHANG ANGLE IN TIG WELDING-BASED WIRE ARC ADDITIVE MANUFACTURING PROCESS
}

\author{
Omer Eyercioglu *1, Yusuf Atalay ${ }^{1}$, Mehmet Aladag ${ }^{1}$ \\ ${ }^{* 1}$ Department of Mechanical Engineering, Gaziantep University, Gaziantep, Turkey
}

\begin{abstract}
Wire Arc Additive Manufacturing (WAAM) is a relatively new manufacturing method. It is a novel technique to build net-shaped or near-net-shaped metal components in a layer-by-layer manner via applying metal wire and selection of a heat source such as laser beam, electron beam, or electric arc. WAAM process is preferable as an alternative to traditional manufacturing methods especially for complex featured and large scale solid parts manufacturing and it is particularly used for aerospace structural components, manufacturing and repairing of dies/molds. TIG weldingbased WAAM method is implemented by depositing continuous wire melted via heat. In this study, the overhang (self-supporting) angle in TIG welding-based wire arc additive manufacturing process is investigated. The overhang angles are the angles at which a 3D printer can build tapered (overhang) surfaces without the need to supporting material below the printing layer. The material, bead height, TIG weld parameters and the environment temperature (cooling rate of printed layer) are the parameters which affect the overhang angle. The results show that the maximum overhang angle is also dependent on the temperature of the previous layer. For the selected set of process parameters, the maximum overhang angle is found as $28 \mathrm{o}$, if the temperature of the previous layer is cooled to $150 \mathrm{oC}$ before the subsequent layer is deposited.
\end{abstract}

Keywords: TIG Welding; Wire Arc Additive Manufacturing; Overhang; 3d Printing.

Cite This Article: Omer Eyercioglu, Yusuf Atalay, and Mehmet Aladag. (2019). "EVALUATION OF OVERHANG ANGLE IN TIG WELDING-BASED WIRE ARC ADDITIVE MANUFACTURING PROCESS." International Journal of Research - Granthaalayah, 7(10), 247-254. https://doi.org/10.29121/granthaalayah.v7.i10.2019.393.

\section{Introduction}

Wire arc additive manufacturing (WAAM) is a relatively new manufacturing method [1]. The method presents a flexible, fast and cost-effective alternative to the traditional manufacturing methods especially for complex featured and large scale solid parts. Due to these advantages the method is particularly preferred for aerospace structural components, manufacturing and repairing of dies/molds [2-5]. The early studies on the WAAM process were used to overcome the difficulties in powder-bed additive manufacturing systems by wire feed and powder together [68]. The process was initially patented by Roll-Royce with the name as shaped metal deposition 
technique, further progress which was made at welding engineering research center (WERC) in Sheffield University [9]. Nowadays, the term refers to all the processes which use metal wire-feed as a deposition material associated with one of the main energy sources such as laser beam, electron beam, and electric arc beam [1].

In TIG welding-based WAAM process, metallic components are manufacturing by melting a cold wire using heat of arc and depositing beads of weld metal on a substrate in layer by layer according to the generated tool path [10]. The WAAM technology produces fully dense parts that are particularly difficult-to-machine and expensive alloys such as Ti-6Al-4V, Inconel 718, TiAl, high grade of stainless steels, etc. [11-14].

As an alternative to traditional manufacturing processes, the additive manufacturing brings its own design and manufacturing standards. Major aspects introduced by the additive manufacturing process are usually residual stresses, material anisotropy and the printability of overhanging structures [15]. The overhanging structures are printable up to a certain angle, depending on the type of additive manufacturing process and material. There are some guidelines presented by the 3D printer manufacturing companies which are particular for type of process and material. Generally, an overhang angle higher than 450 from the vertical surface plane cannot be printed without supporting [16]. Different strategies for design of printable parts considering the overhang constraints have been proposed; such as density gradient-based [17], robust gradient-based [18] and different variations of topology optimizations [19-21]. The purpose of the presented study is to investigate the overhang (self-supporting) angle in TIG welding-based wire-arc additive manufacturing process. For this purpose an experimental work is carried out using the TIG welding-based WAAM system which had designed and constructed previously in the Department of Mechanical Engineering of Gaziantep University.

\section{Overhang Angle in Additive Manufacturing}

In design of parts for additive manufacturing there are some guidelines to be followed for achieving required quality. Many researchers have been focused on to establish these guidelines, depending on the material and the printing methods. One of the constraints of the printable geometry is the overhang angle. Overhang (self-supporting) angles are the angles at which a 3D printer can build tapered (overhang) surfaces without the need to supporting material below the printing layer. It can be described simply by building an upside down staircase, as shown in Figure 1. In TIG welding-based wire-arc additive manufacturing process (WAAM), it is impractical to use support material due to penetration of the deposit to the support, the permanent bonding may not be removable after building. Therefore, determination of the overhang angle for TIG weldingbased wire-arc additive manufacturing process (WAAM) presents acceptable guidelines to the designer.

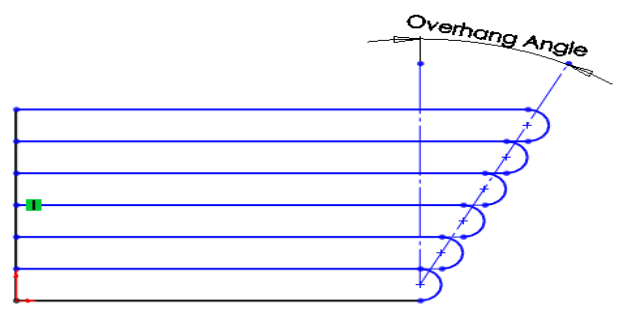

Figure 1: Overhang Angle 


\section{Experimental Study}

\subsection{TIG Welding-Based Wire-Arc Additive Manufacturing (WAAM) System}

In this study, the WAAM system [1] which had designed and constructed previously in the Department of Mechanical Engineering of Gaziantep University was used. The main units of the WAAM-system are shown in Figure 2. The WAAM machine has 3D linear axes (XYZ) which are used for depositing melted wire to produce 3D solid parts. The melting source is electric arc where heat is generated between workpiece (substrate or previous layer) and the tungsten electrode. The welding machine has a capability of producing AC/DC, pulsed /non-pulsed current TIG welding. The deposition tool (DT) unit is a fixture that is used to attach the welding torch and the wire feed nozzle (see Figure 3). The wire feeding unit controls the wire speed. The movements of the WAAM machine axes are controlled by a CNC control system. The general hardware structure of the WAAM system is shown in Figure 4. The WAAM machine in the figure represents the central part of the WAAM hardware system.

\subsection{Materials and TIG-Weld Parameters}

St-37 structural steel sheet with $100 \times 100 \times 6 \mathrm{~mm}$ dimensions was used as the substrate (the base plate) material. The substrates were mechanically cleaned to remove the possible grease, paint, rust, etc. The deposition wire was chosen according to AWS A5.9-95 specification; ER308LSi grade, $0.8 \mathrm{~mm}$ diameter low carbon grades solid stainless steel wire. These materials have good arc characteristics, weld pool fluidity as it contains higher $\mathrm{Si}$, and flatten weld bead profile.

Argon with a $99.90 \%$ purity was used as the inert gas for shielding. The shielding gas (Ar) which surrounds the electrode and the weld pool forms an inert atmosphere which protects the electrode and the workpiece from atmospheric contamination and favor in the ignition and stability of the arc.

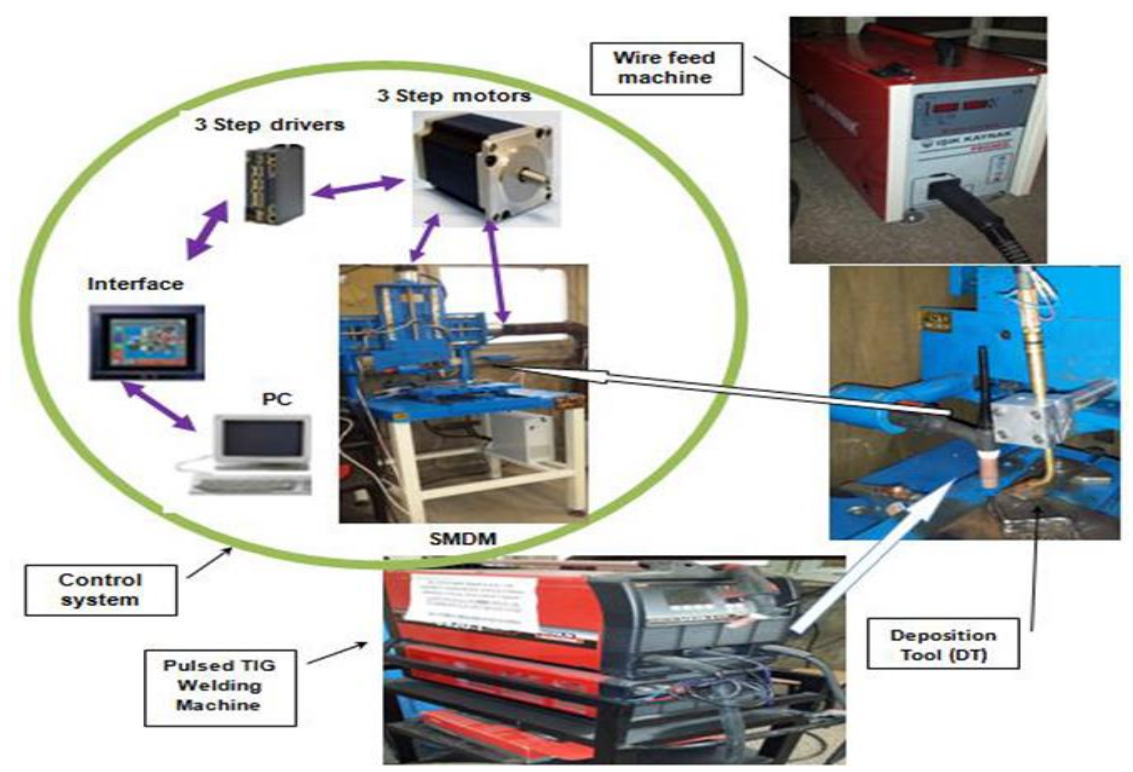

Figure 2: Main integrated units in WAAM system [1] 


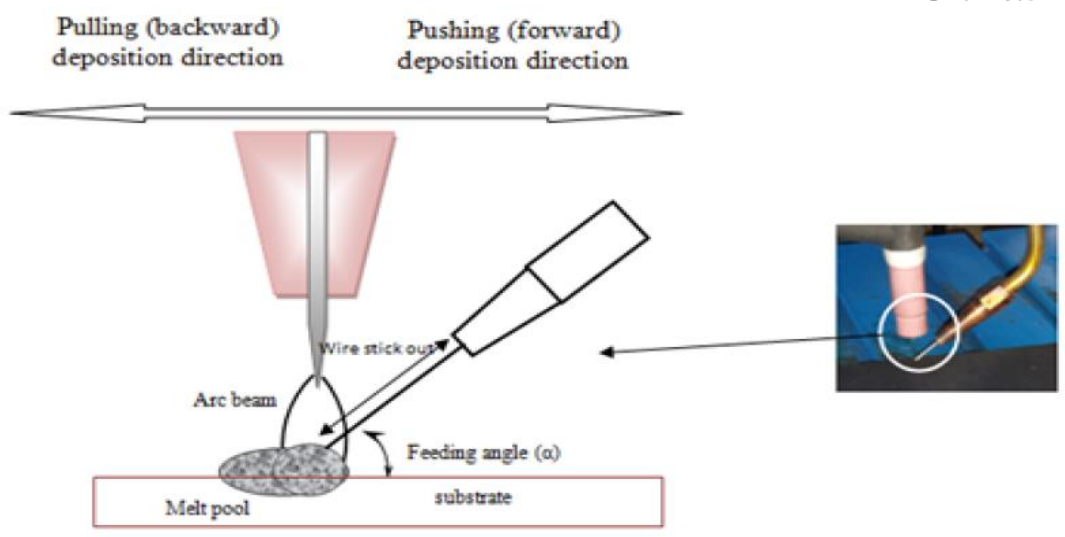

Figure 3: The wire arc deposition system

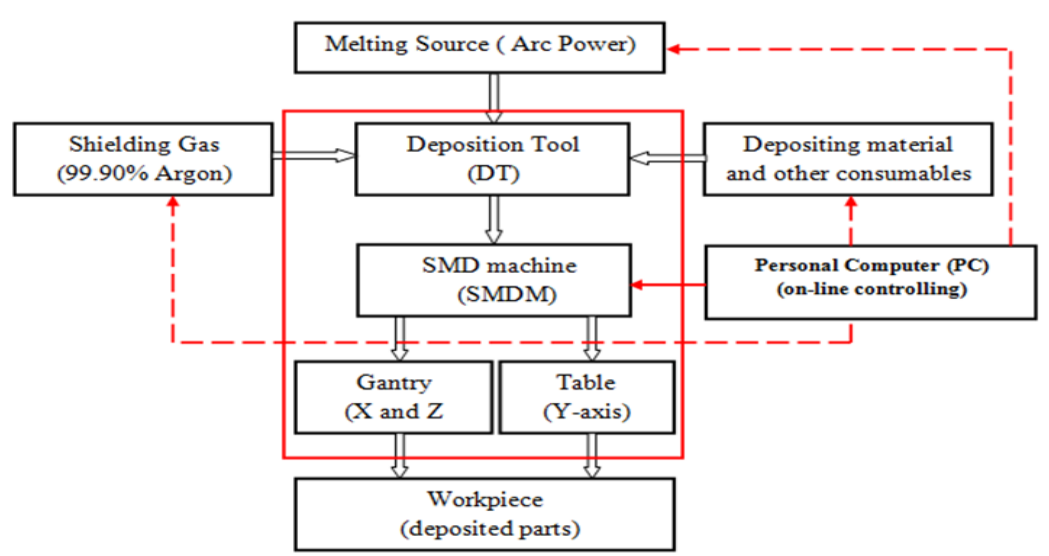

Figure 4: Work cell structure in CAMDM hardware [1]

\subsection{Dimensional and Temperature Measurements}

The dimensions of the deposited shape (height, width, diameter and overhang angle) were measured by using a Kemco 3D coordinate measurement machine (CMM). Temperature measurements were carried out using a thermal camera (Tesco 875-2i) and a laser pyrometer (Trotec TP10) were used for thermal images of the process and the temperature measurements. The captured thermal images were analyzed using Tesco IRSoft software.

\subsection{Experimental Procedure}

To investigate the overhang angle, semi-circular shapes with different tapered angles were manufactured by using the TIG welding-based WAAM system. The diameter of each subsequent layer is increased accordingly to obtain a pre-determined overhang angle. Prior to the deposition, it is necessary to carefully tune the main process parameters and conditions such as arc current (I), arc length (L), travel speed (TS), and wire feed speed (WFS). It is essential to know that these factors have to be chosen as suitable as a combination to reach process stability. There are other important conditions which also affect the deposition quality such as shielding gas flow rate, the wire's feeding angle $(\alpha)$, wire feed direction, and position of the wire tip in the weld pool. These parameters control the amount of heat input, metal deposition rate, and the beads geometry. 
Considering the volume of the presented study, preliminary studies were carried out to determine the process parameters for process stability. Therefore, some of these parameters were kept constant and the increase in diameter (so as the overhang angle) was chosen as variable during the experimental work. The process parameters are summarized in Table 1 and the deposition and overhang angle are schematically shown in Figure 5.

Table 1: Process Parameters

\begin{tabular}{|l|l|}
\hline Input parameter & Value \\
\hline Welding Current & $63 \mathrm{~A}$ \\
\hline Travel speed & $60 \mathrm{~mm} / \mathrm{min}$ \\
\hline Wire feed speed & $60 \mathrm{~mm} / \mathrm{sec}$ \\
\hline Feeding angle $(\alpha)$ & 350 \\
\hline Arc length $(\mathrm{L})$ & $5 \mathrm{~mm}$ \\
\hline Initial radius of deposition path & $25 \mathrm{~mm}$ \\
\hline Increase in radius in subsequent layer & $1 \mathrm{~mm}, 1.5 \mathrm{~mm}, 2 \mathrm{~mm}$ \\
\hline Shielding gas $($ Ar) flow rate & $12 \mathrm{liters} / \mathrm{min}$ \\
\hline
\end{tabular}

\section{Results and Discussions}

\subsection{Temperature Measurements}

A photograph after first layer deposition of TIG welding-based WAAM system is shown in Figure 6. The temperature-time history of the midpoint of the first layer is shown in Figure 7(a). The temperature measurement was taken after the WAAM machine was shut off due to overcome the high emissivity of the arc. The thermal image after second layer deposition is given in Figure 7(b). Figure 8 shows the time evolution of the temperature of the extruded deposit 1-6 layers at the midsection. As a new layer is deposited, the temperature of the adjacent layers increases so their cooling is delayed. Each peak was followed by rapid decrease in temperature as the extrusion head moved away from the center position of the part. The temperature of the mid-section was gradually increasing during the process; this shows that cooling may be required during process to keep the shape of the part.

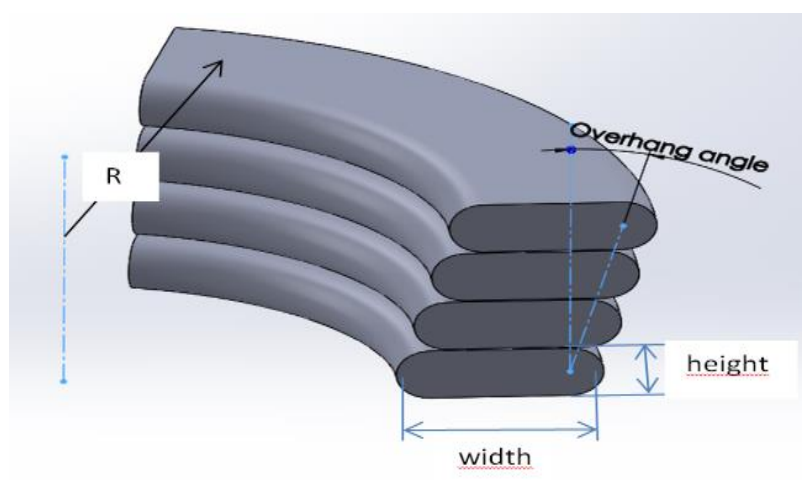

Figure 5: Schematic view of deposition and overhang angle

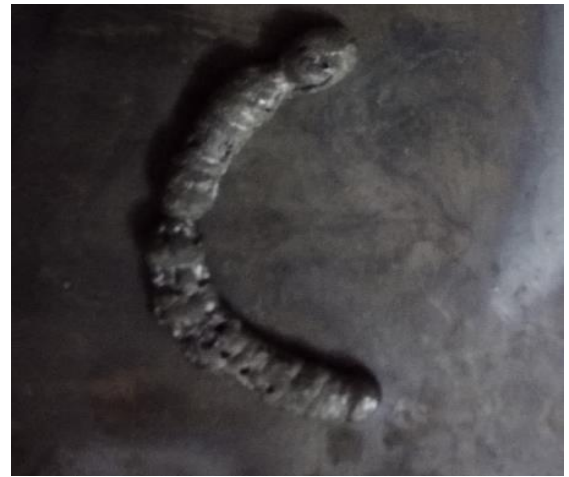

Figure 6: A photograph after first layer deposition of TIG welding-based WAAM system 


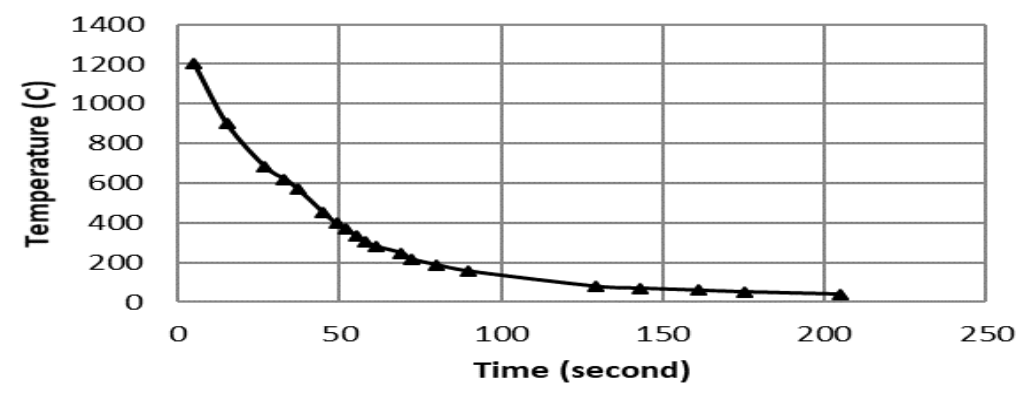

(a)

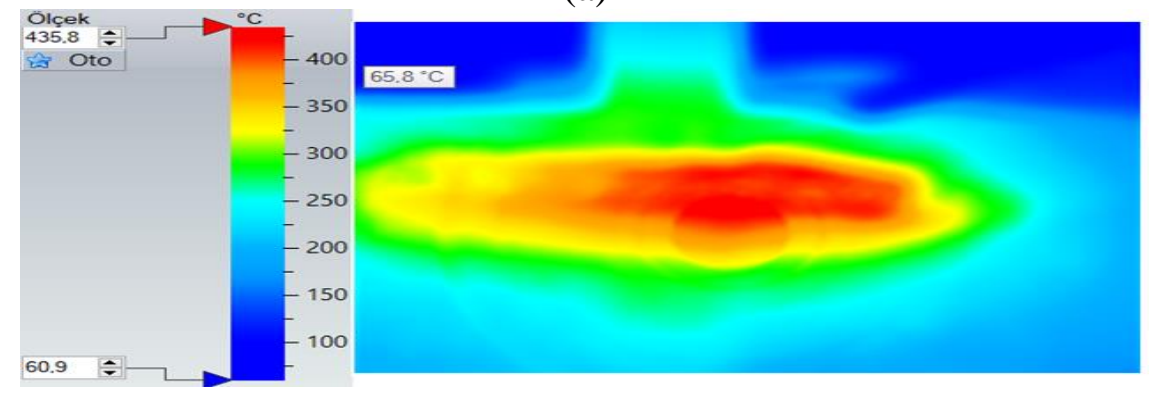

(b)

Figure 7: (a) Cooling curve of the first deposited layer (b) Thermal image after deposition of second layer)

\subsection{Overhang Angle}

A photograph of the printed part with $1 \mathrm{~mm}$ increase in the radius of subsequent layer is given in Figure 9. The layer radii, heights and the widths are given Table 2. The heights of the deposited layers are slightly decreasing as the additional layers are deposited. This is due to penetration of the subsequent layer on the previous one. The penetration rate may change because of the temperature increase of the part during process. The widths of layers are increasing according to the volume constancy. The overhang angle is measured as 24.5 degrees.

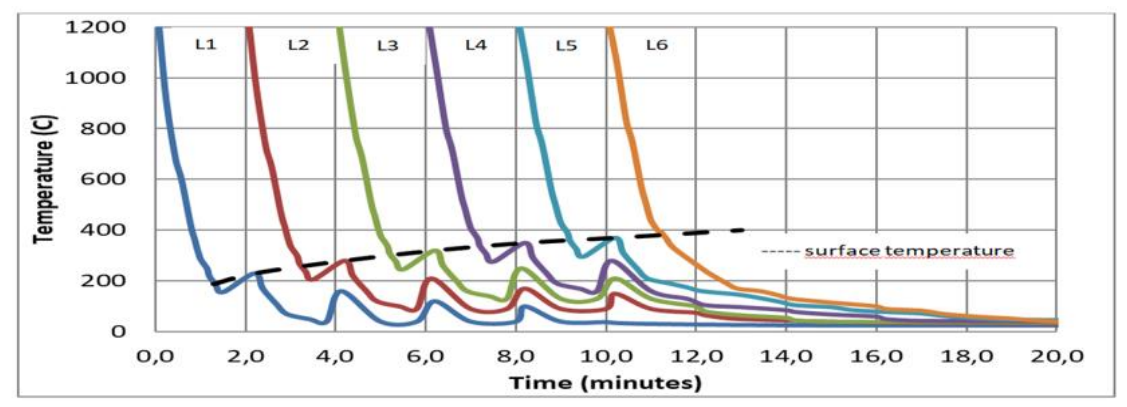

Figure 8: The time evolution of the temperature of the extruded deposit 1-6 layers at the midsection

In the second experiment, the increase in radius was taken as $2 \mathrm{~mm}$, unfortunately the deposits were not kept their positions, sag down to the outer circumference of the part and then flowed as droplets. The increase in radius was the chosen as $1.5 \mathrm{~mm}$ in the third experiment. The shape is better than the $2 \mathrm{~mm}$ increasing, but flow of material on the surface of the outer circumference of the part was observed. There were no droplets in this case. 
The surface temperature of the previous layer is an important parameter in the success of the deposition. Taking the time evolution of the temperature of the extruded deposit (Figure 8) into account, the authors decided that to wait until the temperature of the previous layer cool down to $150 \mathrm{oC}$ before deposit the subsequent layer. The result of this experiment is successful; no sag down of the deposit was observed. The overhang angle was measured as 28 degrees.

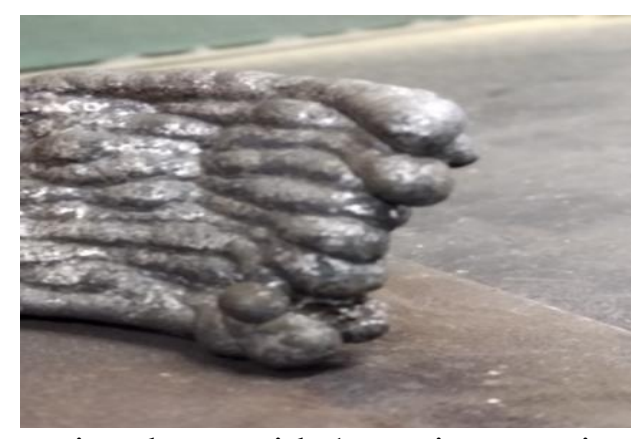

Figure 9: A photograph of the printed part with $1 \mathrm{~mm}$ increase in the radius of subsequent layer

Table 2: Variation of height and width of deposition with respect to layers

\begin{tabular}{|l|l|l|l|}
\hline Layer & Radius (mm) & Height $(\mathbf{m m})$ & Width $(\mathbf{m m})$ \\
\hline 1 & 25 & 4 & 7.4 \\
\hline 2 & 26 & 7.5 & 7.9 \\
\hline 3 & 27 & 10.8 & 8.2 \\
\hline 4 & 28 & 14 & 8.5 \\
\hline 5 & 29 & 17 & 8.7 \\
\hline 6 & 30 & 19.8 & 9.0 \\
\hline 7 & 31 & 22.4 & 9.3 \\
\hline 8 & 32 & 24.6 & 9.6 \\
\hline 9 & 33 & 26.8 & 9.9 \\
\hline 10 & 34 & 28.8 & 10.3 \\
\hline 11 & 35 & 30.7 & 10.6 \\
\hline 12 & 36 & 32.2 & 11.0 \\
\hline
\end{tabular}

\section{Conclusions}

In most of the additive manufacturing methods, maximum overhang angle was taken as 45o. In wire arc additive manufacturing (WAAM), the expectation was lower due to the higher temperature of the arc. In this study, the overhang angle of a semicircular shape was investigated experimentally by using the TIG welding-based WAAM system. The results show that the maximum overhang angle is dependent on the temperature of the previous layer. For the selected set of process parameters, the maximum overhang angle is 28 degrees, if the temperature of the previous layer is cooled to $150 \mathrm{oC}$ before the subsequent layer is deposited. Further studies are needed to determine the limits of overhang angles for various process parameters (welding current, travel speed, bead height, wire diameter and feed rate).

\section{Acknowledgements}

The authors would like to acknowledge the contributions of the Scientific Project Bureau (BAPYB) of The Gaziantep University. 


\section{References}

[1] Yilmaz, O., Almusawi, A. R. J., Ugla, A. A., and Keskin, O. O. "Design, Construction, and Controlling of A Shaped Metal Deposition Machine Using Arc Metal-Wire System", Issue June 2015, 2016.

[2] Antonysamy, A. A. Microstructure, Texture and Mechanical Property Evolution during Additive Manufacturing of Ti6Al4V Alloy for Aerospace Applications, 2012.

[3] Buckner, M. A. and Love, L. J. In Automating and accelerating the additive manufacturing design process with multi-objective constrained evolutionary optimization and HPC/Cloud computing, IEEE: 2012.

[4] Wohlers, T. "Rapid Prototyping 7 Tooling State of the Industry", Wohlers Report, 2002.

[5] Mahamood, R., Akinlabi, E., Shukla, M., and Pityana, S. "Laser metal deposition of Ti6Al4V: A study on the effect of laser power on microstructure and microhardness", 2013.

[6] Syed, W. U. H., Pinkerton, A. J., and Li, L. "Combining wire and coaxial powder feeding in laser direct metal deposition for rapid prototyping", Applied Surface Science, Vol. 252, Issue 13, Pages 4803-4808, 2006.

[7] Syed, W. U. H. , Pinkerton, A. J. , and Li, L. "Simultaneous wire- and powder-feed direct metal deposition: An investigation of the process characteristics and comparison with single-feed methods", Journal of Laser Applications, Vol. 18, Issue 1, Pages 65-72, 2006.

[8] Brandl, E., Leyens, C., and Palm, F. "Mechanical Properties of Additive Manufactured Ti-6Al-4V Using Wire and Powder Based Processes", IOP Conference Series: Materials Science and Engineering, Vol. 26, Pages 012004, 2011.

[9] Rapolac Project. http://www.rapolac.eu

[10] Bonaccorso, F., Bruno, C., Cantelli, L., Longo, D., and Muscato, G. "Control of a shaped metal deposition process", Physics Conference (PHYSCON), Pages 1-5, 2009.

[11] Bonaccorso, F., Cantelli, L., and Muscato, G. "An Arc Welding Robot Control for a Shaped Metal Deposition Plant: Modular Software Interface and Sensors", IEEE Transactions on Industrial Electronics, Vol. 58, Issue 8, Pages 3126-3132, 2011.

[12] Muscato, G., Spampinato, G., and Cantelli, L. In A closed loop welding controller for a rapid manufacturing process, IEEE: 2008.

[13] Merz, R., Ramaswami, Terk, K., and Weiss, M. "Shape Deposition Manufacturing", The Solid Freeform Fabrication Symposium, Pages 1-7, 1994.

[14] Skiba, T., Baufeld, B., and Biest, O. van der "Microstructure and Mechanical Properties of Stainless-Steel Component Manufactured by Shaped Metal Deposition", ISIJ International, Vol. 49, Issue 10, Pages 15881591, 2009.

[15] Hoffarth, M., Gerzen, N., and Pedersen, C. "ALM Overhang Constraint in Topology Optimization for Industrial Applications", 12th World Congress on Structural and Multidisciplinary Optimisation, Issue June, Pages 1-11, 2017.

[16] Roschli, A. , Gaul, K. T. , Boulger, A. M. , Post, B. K. , Chesser, P. C. , Love, L. J. , Blue, F. , and Borish, M. "Designing for Big Area Additive Manufacturing", Additive Manufacturing, Vol. 25, Pages 275-285, 2019.

[17] X. Qian, "Undercut and overhang angle control in topology optimization: A density gradient based integral approach", International Journal for Numerical Methods in. Engineering, 1097-1207, 2017.

[18] K. Svanberg, "The method of moving asymptotes - a new method for structural optimization", International Journal for Numerical Methods in Engineering, 24(2), 359-373, 1987.

[19] A.T. Gaynor, "Topology optimization algorithms for additive manufacturing", Doctoral dissertation, The Johns Hopkins University, Baltimore, US-MD, 57-84, 2015.

[20] M. Langelaar, "Topology optimization of 3D self-supporting structures for additive manufacturing", Additive Manufacturing, 12 (A), 60-70, 2016.

[21] M. Langelaar, "An additive manufacturing filter for topology optimization of print-ready designs", Structural and Multidisciplinary Optimization, 55 (3), 871-883, 2017.

*Corresponding author.

E-mail address: eyercioglu @gantep.edu.tr 